\title{
SCANNING AND TRANSMISSION ELECTRON MICROSCOPIC OBSERVATIONS OF A CONGENITAL EPULIS
}

\author{
HIDEZIRO INOUE, TAMAKA OKINA, MASAZUMI TAKENAKA, \\ FUTOSHI MORINAGA, HIDEKI KAWAHARA, TAKUMI MIYAGI, \\ HIROKAZU KITAGAWA ${ }^{1)}$, HIDEO KAWAHARA ${ }^{2)}$ \\ AND YOUSUKE KITAHARA ${ }^{3)}$
}
Department of Oral Surgery"1, Second Department of Anatomy ${ }^{21}$ and Electron Microscope Laboratory ${ }^{3)}$, Kurume University
School of Medicine, Kurume, 830, Japan

Received for publication December 15, 1977

\begin{abstract}
We observed, under the scanning and transmission electron microscope, the case of a bean-size tumor which developed from the moment of his birth in the front tooth area of the lower jaw of a male new-born baby of 37 days.

Clinically it was diagnosed as a case of congenital epulis and histopathologically confirmed the congenital fibromatosis.

The observation under the scanning electron microscope revealed that the tumor consisted of basically fibrous connective tissue and partly of osseous formation structure. Transmission electron microscope served to observe the variety of fibroblast patterns such as fusiform, stellated and plane one etc., as well as the existence of abundant reticular and collagenous fibrils in its stroma.

These findings under both electron microscopes suggest to consider on the hamartoma character of the tumor from mesenchymal tissue.
\end{abstract}

\section{INTRODUCTION}

The congenital epulis is a rather rare tumor of the gums of a new-born baby. The reported cases of the referred tumor are few in our country, only two cases have been found in the Department of Oral Surgery over the lapse of the past 16 years.

This is a report of one of the above mentioned two cases, histopathologically diagnosed as congenital fibromatosis, which was through observed under the scanning and transmission electron microscopes.

\section{CASE REPORT}

The patient, a new-born baby of 37 days old, whose inferior maxilla showed a bean-sized tumor located on the labial side of the front tooth of the gums at the moment of birth. The tumor was pedunculated, smooth on its surface, red-purple colored and had an elastic consistence (Figs. 1 and 2).

Once the clinical diagnosis of congenital epulis was made, we performed its totally extirpation under the local anesthesia. The extirped material showed the following features : $0.6 \times 0.6 \times 0.3$ 
$\mathrm{cm}$ in size, weight $200 \mathrm{mg}$ and a compound of two layers; the whitish linear substance distinguished from the yellowish-gray exterior layer and the whitish transparent inner one.

The histopathological diagnosis was congenital fibromatosis.

\section{METHODS}

As a material for the study by scanning electron microscope, part of the extirped material was fixed in $2.5 \%$ glutaraldehyde in $0.1 \mathrm{M}$ cacodylate buffer at $4^{\circ} \mathrm{C}$, and post fixed in $1 \%$ osmium tetraoxide. The fixed specimen were dehydrated in an ascending series of alcohol and immersed in the isoamyl acetate, with critical point drying method. Following gold ion-spattering specimens were observed by the Hitachi HFS-2 type (Yamada et al., 1976).

On the other hand, the specimen to be examined by the transmission electron microscope were made from the remaining part of the tumor tissue, according to the conventional preparing method, and observed with the Hitachi $\mathrm{Hu}-12 \mathrm{As}$ type. We also prepared specimen with hematoxylin-eosin staining for the light microscopic examination.

\section{OBSERVATIONS}

\section{Light microscopic findings}

The sections showed a remarkable proliferation of fibrous connective fibrils below the stratified squamous epithelium; also there were occasional findings of osseous formations, and contacting to this osseous formation structure an infiltration of inflammatory cells were observed (Fig. 3).
Findings in scanning electron microscope

The observation of the tumor's tissue in its longitudinal section revealed its components of mucous membrane and lamina propria; the mucous membrane was a stratified squamous epithelium which consisted of corneum, granulosum, spinosum and germinativum layer, and the mucous membrane seemed to maintain in an even range with occasional elongation intermingled into the lamina propria (Fig. 4).

In the lamina propria we observed an exceeding proliferation of collagenous and reticular fibrils, as well as numerous capillary vessels and mesenchymal cells of different sizes and forms among them. Also in the basal part section of the tumor, we found a dense and uniformally conglomerated mass substance of an osseous formation (Figs 4 and 5). The observation of this osseous formation, once it was high a magnified, revealed that it consisted of a dark density central part which became gradually clear towards the periphery, to be finally surrounded by light density, round shaped cells and abundant reticular fibrils. Mainwhile the capillary vessels, closely situated to the osseous formation, were partly enlarged and their endothelium was distended to take an oval shape in the part which included the nucleus, and it showed a varying morphology accordingly to the different sections. As for the numerous mesenchymal cells found in the lamina propria, they were of round or oval shape, as shown in Fig. 6. Surrounding them, we found also abundant collagenous and reticular fibrils making varying formations, such as snake-, whirpool- or bundlelike ones, but there wasn't any ruling in their arrangement, nor in their size. 


\section{Findings in transmission electron microscope}

The same material used for the scanning electron microscope, mentioned above, was used for the study under the transmission electron microscope. Also for this study, we employed the material of contacting tumor tissue. We found that the tumor tissue's cells group consisted largely of ordinary fibroblast-like cells, such as fusiform, plane, and stellated patterns; they were intermingled partly with the differentiated fibroblast-alike cells which were large in size, with round shape, and rather large nucleus, while contained numerous vesicles, tubular rough surfaced endoplasmic reticulum, free ribosomes, and mitochondria, etc in the cytoplasm (Figs. 7 and 8).

In other words our findings were enough to make us think that these cells were in the process of proliferation and differentiation to become finally a common matured fibroblast.

\section{DISCUSSION}

A few number of cases of congenital epulis have been reported since Neumann observed the first case in 1871. According to the reference of Ito et al. (1976) approximately 20 cases have been reported in our country.

Our case did not differ basically in its clinical findings from those cases reported by some investigators (Custer and Fust, 1952 ; Ito et al., 1976 ; Matsuda and Kobayashi, 1955 ; Ofuji and Sato, 1974), notwithstanding its histopathological features differed from the granular cell myoblastoma that was habitually observed by them.

What we found in return, was a remarkable proliferation of fibrous connective tissue and occasional osseous formation. Two discordant theories are prevailing about the histological origin of this tumor: they are theories of dental germ origin and non-dental germ origin ones. Among the few reports about this disease as being studied under the electron microscope, we referred ourselves to that of Kawamura et al. (1971) in which they mentioned the possibility of alterated formation of fibrous connective tissue, based on the findings of well developed, small collagenous fibrils and fibroblast cells under the transmission electron microscope. Our findings were similar to those of Kawamura et al. (1971) as well as the well developed fibroblast in their varying process of differentiation. But besides these findings, we found also a remarkable proliferation of collagenous and reticular fibrils which called our attention.

Under the scanning electron microscope we also recognized in the central part of the basal layer of the material of laminal structure, meaning an osseous formation. The conglomeration of reticular fibrils and round cell groups seemed to be the consequence of alterated metabolic substances, caused by local inflammation, though we could not find any relationship between the above mentioned and the germ of deciduous tooth or the alveolar bone located right below it. The currently studied case of congenital epulis differed also from our previous case (Okina et al., 1977). Under the scanning and transmission electron microscope, we found that the tumor consisted basically of fibrous connective tissue, being far from similar to the previous case which was a gathering of granular cell and epithelium. Based on those facts, we suppose a sort of hamartoma character of the tumor which might be stemmed from the mesechymal tissue. Matsuda and Kobayashi (1955) share our 
opinion, when they report that the congenital epulis should not show necessarily an identical histological pattern.

(Presented before the 22th Annual Session of the Japanese Society of Oral Surgeons, Tokyo, October 23, 1977.)

\section{ACKNOWLEDGEMENTS}

We express our gratitude to Professors M. Murakami and C. Sujaku for their constant interest and counsel, and to Associate Prof. T. Kameyama for his encouragement.

This study was partially supported by the Grant-in-Aid for Scientific Research Project No. 267304 and 277613 from the Ministry of Education.

\section{REFERENCES}

Custer, R. P. and Fust, J. A. (1952). Congenital epulis. Am. J. Clin. Path., 22, 1044-1053.

Ito, K., Kameyama, T., Morinaga, F, Takenaka, M. and Sujaku, C. (1976). Granular cell tumor of the gingiva of a newborn: report of a case. Japan J. Oral. Surg., 22, 506-512.

Kawamura, M., Aida, M., Amamiya, M. and OHASHI, K. (1971). A case of congenital epulis. J. J. S. S., 20, Abstr., 896.

Matsuda, S. and Kobayashi, Y. (1955). A case of congenital epulis. J. Stomatol. Soc, Jpn, 22, 193-197.
OfuJi, Y. and SATo, K. (1974). Congenital epulis: report of a case. Japan J. Oral. Surg., 20, 662-665.

Okina, T., Inoue, H., Fujita, M., Kawahara, $\mathrm{H}$, Motokawa, K., Sujaku, C., Honda, M., HorikaWa, Y., Sakamoto, A. and Ishibashi, M. (1977). Electron microscopic observations on a case of gingival granular cell tumor in newborn. J. J. S. S., 26, 126-138.

Yamada, E., Mizuhira, V., Kurosumi, K. and Nagano, T. (1976). Recent progress in electron microscopy of cells and tissues. pp. 319-342, Igaku-Shoin, Tokyo.

\section{EXPLANATION OF FIGURES}

Fig. 1 Clinical appearance of the patient. Fig. 2 Cut section of the tumor mass.

Fig. 3 Histological view of the tumor with hematoxylin and eosin stain.

Fig. 4 Scanning electron micrograph: The tumor consists histologically of mucous membrane (EP) and lamina propria. $\times 160$

Fig. 5 Scanning electron micrograph of the enlarged part of the capillary vessels (CP) as well as part of the osseous formation structure (OS). $\times 330$

Fig. 6 Scanning electron micrograph showing the proliferation of fibroblast and fibrous components (Rf). $\times 2,000$

Fig. 7 Transmission electron micrograph showing large size of cells which are rich in cell organelle well developed. $\times 15,000$

Fig. 8 Transmission electron micrograph showing the proliferation of the fibroblast alike cells. $\times 8,500$ 

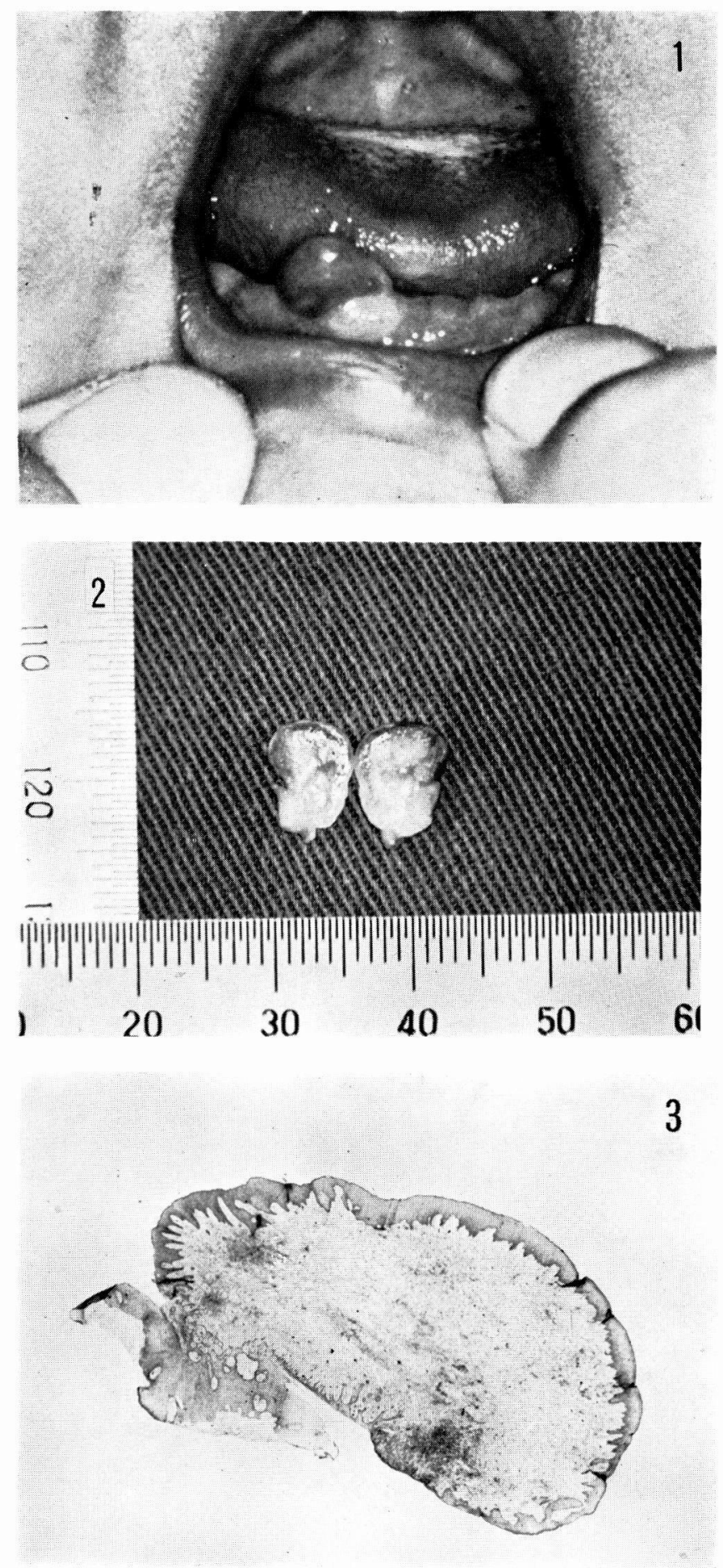


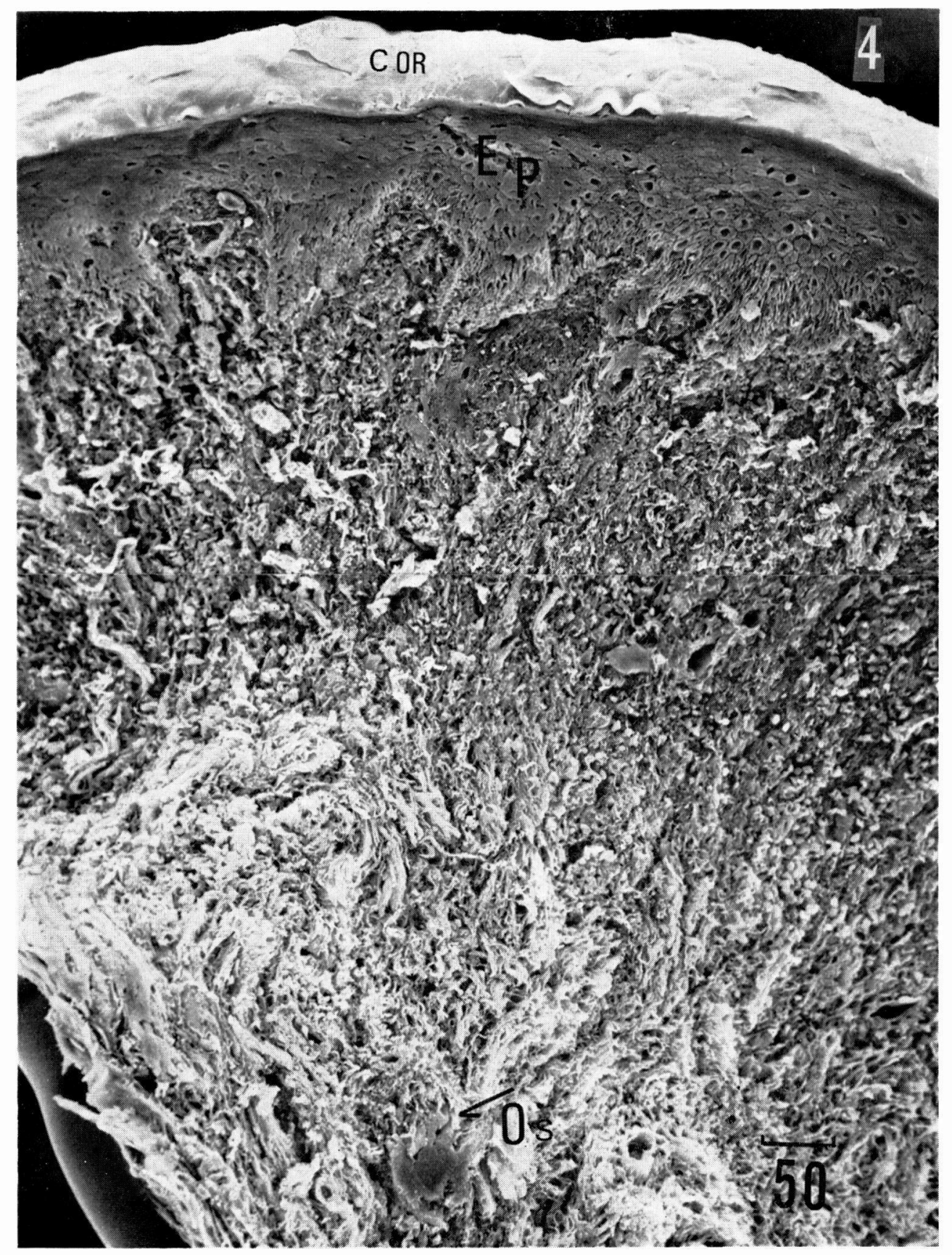



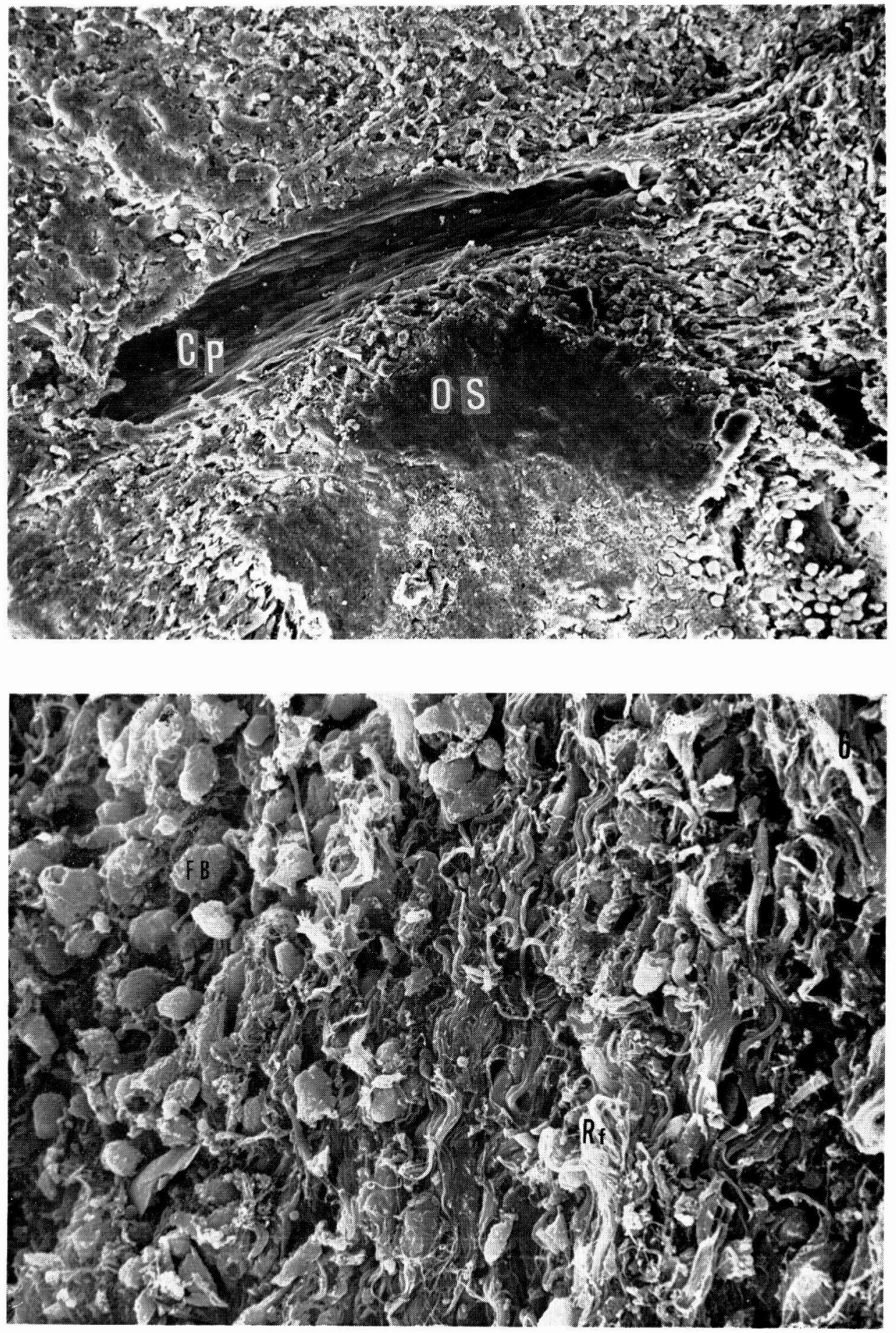

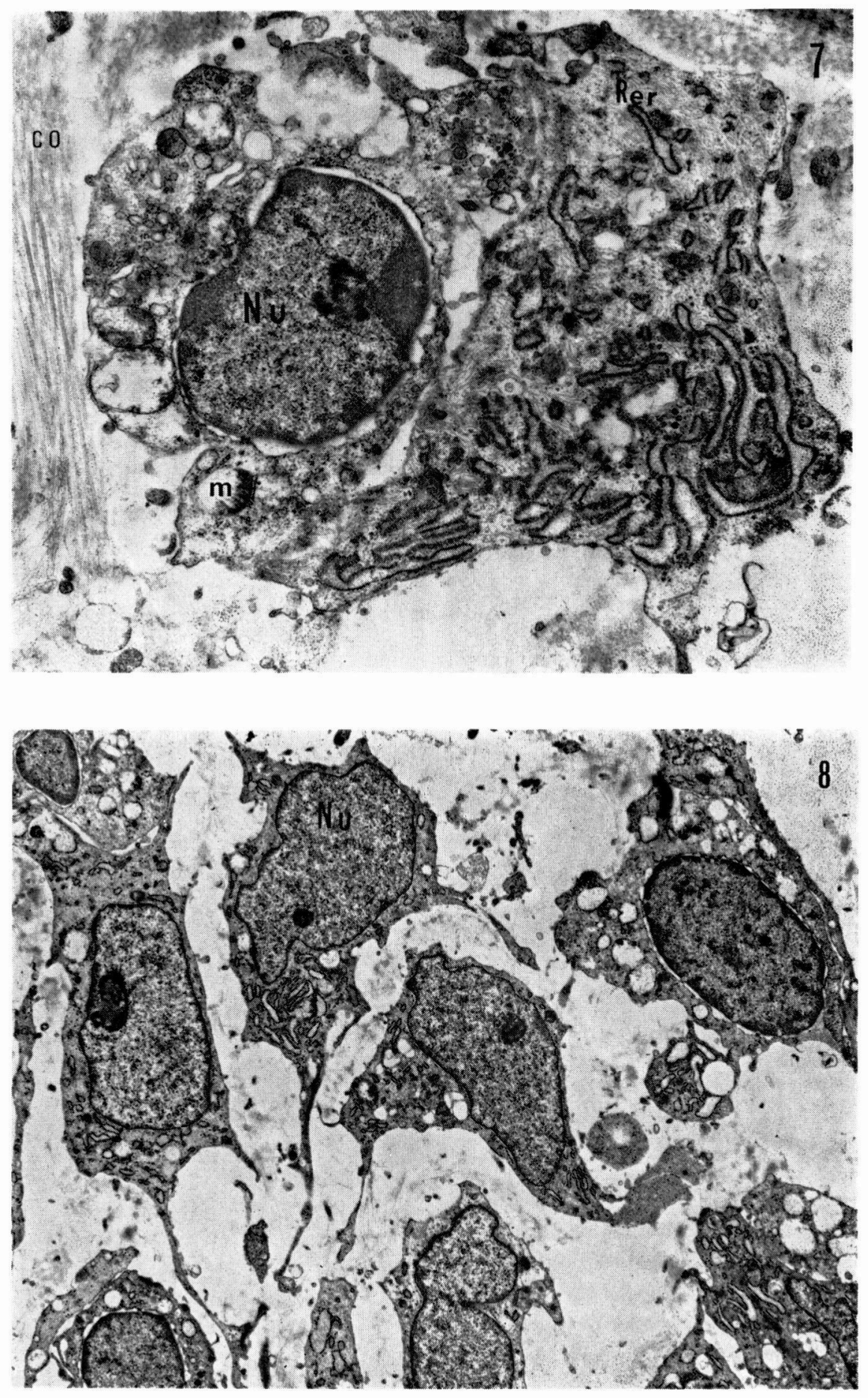